\title{
Demandas dos Cursos de Pós-Graduação em Relação aos Letramentos Aacadêmicos ${ }^{I}$
}

\author{
Maria Izabel Rodrigues TOGNATO* \\ Paula Kracker FRANCESCON** \\ Jacqueline Costa Sanches VIGNOLI***
}

* É docente da Universidade Estadual do Paraná (Unespar), Mestre (2002) em Estudos da Linguagem pela Universidade Estadual de Londrina (UEL), Doutora (2009) em Linguística Aplicada e Estudos da Linguagem pela Pontifícia Universidade Católica de São Paulo (PUC/LAEL). Membro do grupo de pesquisa Linguagem e Educação (LED - UEL/CNPq) e coordenadora do Linguagem, Desenvolvimento, Educação e suas Relações (LIDERE/ Unespar). Contato: maria.tognato@ies.unespar.edu.br.

** É docente da Universidade Estadual de Londrina (UEL), Mestre (2014) e Doutora (2019) em Estudos da Linguagem pela UEL, membro do grupo de pesquisa Linguagem e Educação (LED - UEL/CNPq). Contato: francescon.paula@uel.br.)

*** É docente da Universidade Estadual do Paraná (Unespar), Mestre (2007) em Estudos Linguísticos pela Universidade Estadual Paulista (Unesp) e Doutora (2016) em Letras/Estudos Linguísticos pela Universidade Federal do Paraná (UFPR). Membro dos grupos de pesquisas Linguagem e Educação (LED - UEL/CNPq) e Linguagem, Desenvolvimento, Educação e suas Relações (LIDERE/Unespar). Contato: jacqueline.vignoli@unespar.edu.br.

\begin{abstract}
Resumo:
Considerando a importância dos letramentos acadêmicos ${ }^{2}$ como um conjunto de práticas sociais por meio das quais os significados culturais, as relações de poder e as relações de identidades sociais têm papel central no desenvolvimento social e humano, este trabalho visa a apresentar ações e demandas dos cursos de pós-graduação de duas universidades paranaenses (UEL e Unespar) em relação a experiências desenvolvidas e necessidades referentes aos letramentos acadêmicos. Para tanto, pautamos nossos estudos na perspectiva dos Letramentos acadêmicos, conforme Lea e Street (1998). Os dados foram obtidos por meio de questionários dirigidos a coordenadores/as e gestores/as de programas de pós-graduação das IES participantes do projeto. Os resultados iniciais mostram maior conhecimento de ações em prol dos letramentos acadêmicos em Língua Estrangeira do que em Língua Portuguesa. Além disso, os respondentes assinalaram a necessidade do desenvolvimento de ações relacionadas ao ensino de línguas e à compreensão e produção de gêneros acadêmicos (Resumos, Artigos, Apresentações orais) em língua estrangeira e em língua materna.
\end{abstract}

Palavras-chave:

Letramentos acadêmicos. Universidades paranaenses. Cursos de pós-graduação.

Signum: Estudos da Linguagem, Londrina, v.24, n.1, p. 149-161, abr. 2021

Recebido em: $15 / 10 / 2020$

Aceito em: 18/01/2021

\footnotetext{
${ }^{1}$ Este trabalho vincula-se a um Projeto de Pesquisa mais amplo intitulado Ações de Didatização de Gêneros em prol de Letramentos Acadêmicos, coordenado pela Profa. Dra. Vera Lúcia Lopes Cristovão (UEL/CNPq).

${ }^{2}$ Para fins de delimitação terminológica, utilizamos, neste artigo: a) letramentos acadêmicos (letras minúsculas) para o campo de estudos dos letramentos em contexto acadêmico; b) Letramentos acadêmicos (primeira letra maiúscula) para o terceiro modelo descrito por Lea e Street (1998).
} 


\section{Demandas dos Cursos de Pós-Graduação em Relação aos Letramentos Aacadêmicos}

Maria Izabel Rodrigues Tognato; Paula Kracker Francescon; Jacqueline Costa Sanches Vignoli

\section{INTRODUÇÃO}

A expansão do Ensino Superior, envolvendo mais especificamente a pós-graduação, tem demandado a necessidade de pesquisas vinculadas à discussão sobre as ações linguageiras próprias desse contexto formativo no que diz respeito à apropriação, produção e divulgação de conhecimentos. Assim, considerando tal premência que se impõe aos participantes dos programas de pós-graduação de apresentar e/ou publicar em eventos e/ ou periódicos nacionais e internacionais, propomos uma discussão sobre as concepções de letramentos acadêmicos, constituídas, para além de um conhecimento instrumental, por significados culturais, relações de poder e relações de identidades sociais. Nesse sentido, este trabalho tem como objetivo apresentar e discutir as demandas manifestadas por gestores e coordenadores dos cursos de pós-graduação de duas IES paranaenses, a Universidade Estadual de Londrina (UEL) e a Universidade Estadual do Paraná (Unespar), no que tange às ações existentes às necessidades em prol dos letramentos acadêmicos.

Para tanto, ancoramos nossos estudos na perspectiva dos Novos Estudos de Letramento, em inglês New Literacy Studies (NLS) (BARTON, 1994; GEE, 1996; STREET, 1984; 1994; 1995; 2010), apontando para a relevância das práticas sociais de leitura, escrita e do uso da linguagem, envolvendo diferentes contextos educacionais ou sociais, com o intuito de propiciar um debate social acerca das ações e demandas explicitadas, a partir dos modelos de letramentos acadêmicos descritos por esta abordagem teórica (LEA; STREET, 1998; 2014).

Em relação aos procedimentos metodológicos, no que tange à geração de dados, utilizamos um questionário, enviado a gestores e coordenadores das duas universidades participantes, a fim de obter informações a respeito das ações conhecidas além das possíveis demandas acerca dos letramentos acadêmicos.

Assim, visando a discutir a temática proposta, tomamos alguns questionamentos como norteadores, a saber:

1) Quais são as ações e as demandas mais recorrentes referentes aos letramentos acadêmicos em diferentes cursos de pós-graduação stricto sensu, mestrado e doutorado, na UEL e na Unespar?

2) Quais são os modelos de letramentos acadêmicos (LEA; STREET, 1998) predominantes nas demandas identificadas no contexto de pós-graduação?

Quanto à organização textual, sistematizamos esta discussão nas seguintes partes constitutivas: a) fundamentação teórica norteadora de nosso estudo; b) metodologia por meio da qual apresentamos um trabalho desenvolvido com os dados obtidos e analisados; c) discussão dos resultados das análises; e d) considerações finais. 


\section{Os Letramentos Acadêmicos em Contextos de Pós-graduação}

Considerando que as pesquisas relativas às práticas linguageiras específicas ao Ensino Superior têm obtido uma maior visibilidade (LILLIS; SCOTT, 2007), apontamos algumas explicitações acerca do escopo dos letramentos acadêmicos adotado neste trabalho, tendo em vista a flutuação que tal terminologia apresenta atualmente. Corroboramos os estudos de Fiad (2011, p. 362) ao compreender tal formulação como algo "restrito ao contexto universitário, embora saiba que há práticas de letramento comuns a todos os contextos escolares, sejam da educação básica até a universidade". Tomando por base alguns estudiosos (LEA; STREET, 1998; JONES; TURNER; STREET, 1999), a autora destaca que, ao ingressar na universidade, os estudantes podem ter conflitos entre o que é esperado de suas produções escritas e o que escrevem, uma vez que, partindo de uma compreensão de escrita situada, a entrada na academia representaria um novo contexto de uso da língua, demandando, portanto, práticas até então desconhecidas.

Nessa ótica, os teóricos do campo denominado Novos Estudos de Letramento (cf. STREET, 1984; BARTON, 1994; GEE, 1996), bem como Lea e Street (1998, 1999, 2014), defenderam nova abordagem para a compreensão dos letramentos em contextos acadêmicos. Para esses autores, tal perspectiva poderia ser concebida por meio da sobreposição de três concepções ou modelos: (a) modelo de Habilidades de estudo, (b) modelo de Socialização acadêmica e (c) modelo de Letramentos acadêmicos.

O primeiro, modelo de habilidades de estudo, concebe a escrita e o letramento como habilidade individual e cognitiva. Essa abordagem concentra-se nos aspectos da superfície da forma da língua e pressupõe que estudantes podem transferir seu conhecimento de escrita e letramento de um contexto para outro, sem quaisquer problemas. O segundo, denominado socialização acadêmica, tem relação com a aculturação de estudantes quanto a discursos e gêneros baseados em temas e em disciplinas. Estudantes adquirem modos de falar, escrever, pensar e interagir em práticas de letramento que caracterizavam membros de comunidade disciplinar ou temática. O modelo de socialização acadêmica supõe que os discursos disciplinares e os gêneros são relativamente estáveis e que, tendo os estudantes dominado e entendido as regras básicas de um discurso acadêmico particular, estariam aptos a reproduzi-lo sem problemas. O terceiro modelo, o de letramentos acadêmicos, tem relação com a produção de sentido, identidade, poder e autoridade; coloca em primeiro plano a natureza institucional daquilo que conta como conhecimento em qualquer contexto acadêmico específico (LEA; STREET, 2014, p. 479, grifos dos autores).

Além disso, Lea e Street $(1998,2006)$ propõem um tratamento para a escrita acadêmica a partir dos Letramentos acadêmicos, sobrepondo-se às Habilidades de estudo e da Socialização acadêmica; em outras palavras, para os autores, os letramentos na universidade envolvem o desenvolvimento de práticas sociais referentes à leitura e à escrita de modo mais amplo, para além de habilidades linguísticas. Ademais, de acordo com Lea e Street (2014, p. 479-480), tais “modelos não são considerados exclusivos", mas sobrepostos, sendo "aplicáveis a qualquer contexto acadêmico", possibilitando aos estudantes compreender a utilização dessas "práticas de letramento em cada contexto acadêmico". No entanto, segundo os autores, o modelo de Letramentos acadêmicos ultrapassa os modelos que o antecedem, ao destacar "a relação entre epistemologia e escrita não apenas na área temática geral, mas também, mais amplamente, nas exigências institucionais" no que diz respeito a plágio e feedback, por exemplo, e ao fazerem referência às "exigências individuais dos membros do corpo docente e até mesmo de atribuições individuais de estudante". Para uma maior compreensão da proposta letramentos acadêmicos, sistematizamos suas características constitutivas no Quadro 1. 
Partindo dos três modelos propostos por Lea e Street (1998), entendemos que os dois primeiros modelos isoladamente se caracterizam como limitados para um ensino e aprendizagem mais efetivos no Ensino Superior, pois os próprios autores têm destacado suas limitações, argumentando "que a perspectiva dos letramentos acadêmicos oferece uma visão mais ampla do que está envolvido na produção textual dos alunos e no feedback do corpo docente" (STREET, 2010, p. 546). Por essas razões, corroboramos o posicionamento de Lea e Street por também defendermos o trabalho com gêneros acadêmicos como práticas sociais por meio da construção de sentido, identidade, relações de poder e autoridade.

Quadro 1 - Síntese dos modelos dos letramentos acadêmicos

\begin{tabular}{|c|c|c|}
\hline $\begin{array}{c}\text { Habilidades de estudo } \\
\text { (Destaque para traços formais) }\end{array}$ & $\begin{array}{c}\text { Socialização acadêmica } \\
\text { (Aculturação acrítica ao contexto } \\
\text { acadêmico) }\end{array}$ & $\begin{array}{l}\text { Letramentos acadêmicos } \\
\text { (Práticas sociais de leitura, } \\
\text { escrita e uso da língua) }\end{array}$ \\
\hline $\begin{array}{l}\text { - } \text { domínio das regras gramaticais } \\
\text { e sintáticas, associado à atenção } \\
\text { com pontuação e a ortografia, } \\
\text { garantindo a competência } \\
\text { do aluno quanto à escrita } \\
\text { acadêmica; } \\
\text { domínio dos aspectos } \\
\text { estruturais como caminho para } \\
\text { a aquisição da capacidade de } \\
\text { produzir satisfatoriamente os } \\
\text { gêneros acadêmicos; } \\
\text { ausência de destaque para os } \\
\text { aspectos sociais; } \\
\text { ausência de destaque para as } \\
\text { peculiaridades da escrita em } \\
\text { cada campo disciplinar (escrita } \\
\text { homogênea); } \\
\text { consideração dos textos a } \\
\text { partir de seus traços formais e } \\
\text { superficiais. }\end{array}$ & 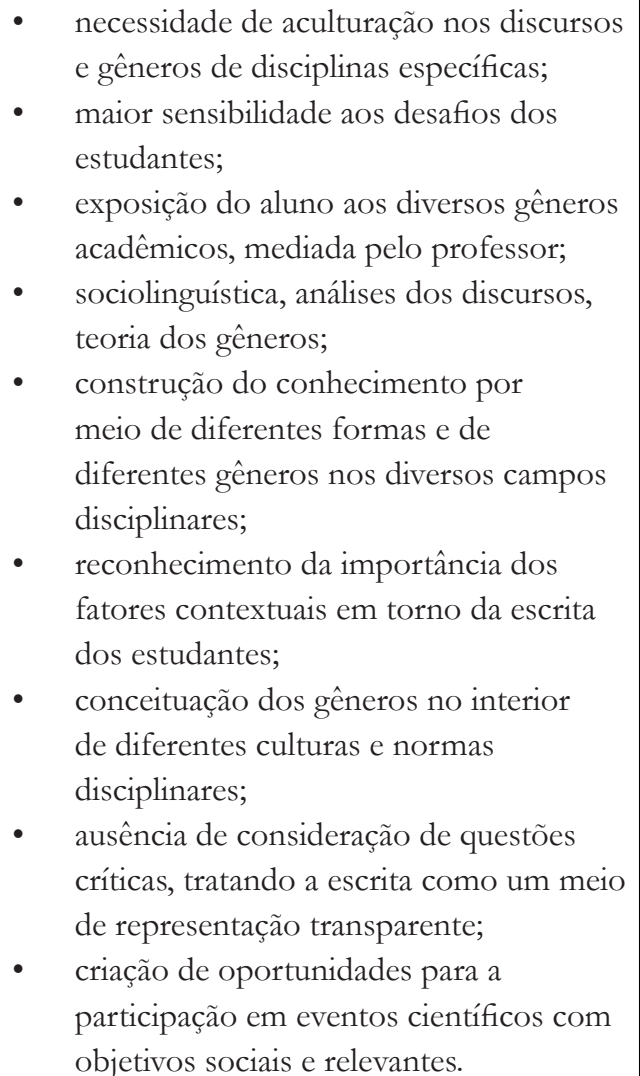 & 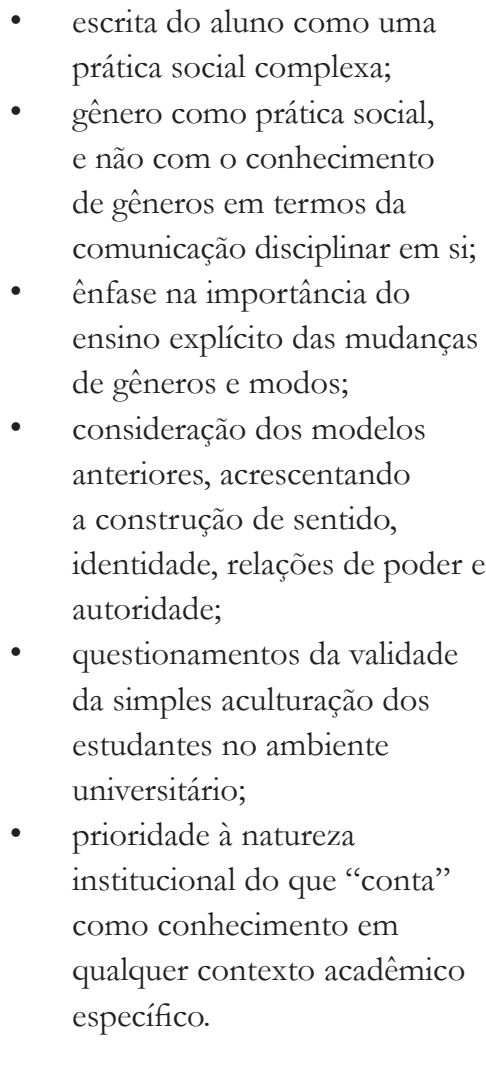 \\
\hline
\end{tabular}

Fonte: As autoras, com base em Lea e Street (1998), Ivanic (2004) e Street (2010, p. 541-567).

\section{Metodologia}

Conforme explicitamos em nossa introdução, este artigo faz parte do projeto de pesquisa $A c ̧ \tilde{e} e s ~ d e$ Didatização de Gêneros em prol de Letramentos Acadêmico, uma experiência de pesquisa colaborativa e em rede, constituída por pesquisadores de quatro instituições de ensino superior públicas paranaenses: Universidade Estadual de Londrina (UEL); Universidade Estadual do Paraná (Unespar); Universidade Tecnológica Federal do Paraná (UTFPR) e Instituto Federal do Paraná (IFPR). Assim, antes de tratar especificamente da metodologia utilizada para geração e análises dos dados deste trabalho, discorremos brevemente, como forma de contextualização, sobre o desenho metodológico do projeto de pesquisa mais amplo.

De acordo com Cristovão e Vignoli (2020), a pesquisa foi desenhada para ser desenvolvida em três fases: i) levantamento de ações e demandas didáticas em prol de letramentos acadêmicos nas 
universidades contempladas; ii) aprofundamento das necessidades, demandas e motivações a partir da apresentação de um plano de ação produzido com base nas análise das demandas mapeadas na primeira fase; e iii) implementação e análise das ações didáticas constante do Laboratório Integrado de Letramentos Acadêmico-Científicos (LILA). A Figura 1 sintetiza as etapas, bem como explicita os instrumentos de pesquisa utilizados:

Figura 1 - Fases de execução e respectivos instrumentos de pesquisa do projeto Ações de Didatização de Gêneros em prol de Letramentos Acadêmico

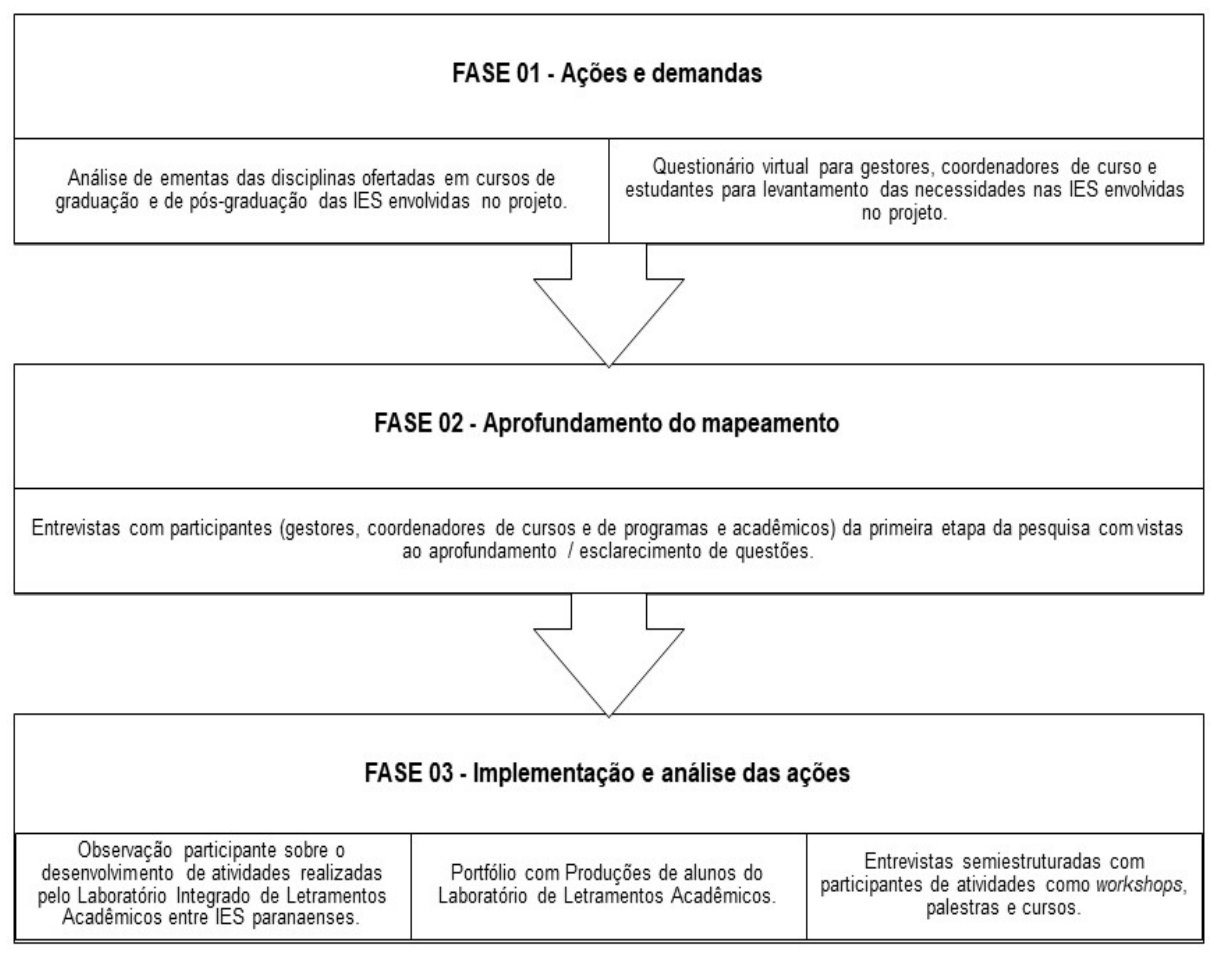

Fonte: As autoras, adaptado de Cristovão e Vignoli (2020).

Neste artigo, nosso foco está na primeira fase do projeto, envolvendo o levantamento de ações e demandas, mais especificamente com a aplicação de questionários virtuais para gestores e coordenadores de cursos de pós-graduação de duas das universidades envolvidas (UEL e Unespar). Do ponto de vista de sua caracterização, trata-se de uma abordagem metodológica mista, uma vez que utilizamos métodos qualitativos e quantitativos para a geração e análise de dados, a fim de melhor compreender o fenômeno estudado (PAIVA, 2019, p. 13).

Os participantes ${ }^{3}$ foram convidados por email e os questionários, aplicados via Google Forms, foram compostos por duas seções: a primeira, referente a informações dos respondentes, como a universidade em que trabalha e sua função; e a segunda, relacionada às ações e às demandas das instituições no que tange aos letramentos acadêmicos. No Quadro 2, apresentamos as perguntas constituintes dos dois questionários, sendo que, na primeira coluna, constam as questões realizadas aos gestores; na segunda, as questões para os coordenadores; e, na terceira, a caracterização do tipo das perguntas.

As questões de 01 a 04 foram formuladas com vistas à compreensão das ações já existentes nas universidades, além das experiências conhecidas pelos participantes em outras IES. Por serem de natureza objetiva (seleção de opções dentre as apresentadas pelas pesquisadoras), o tratamento para esses dados se deu

\footnotetext{
${ }^{3} \mathrm{O}$ convite aos participantes incluiu o envio do projeto de pesquisa e de um Termo de Consentimento Livre e Esclarecido (TCLE), com o qual os participantes consentiram ao preencherem o formulário. O projeto de pesquisa, os instrumentos de geração de dados e o TCLE foram aprovados pelo Comitê de Ética (CAAE 09695319.4.1001.5231).
} 
de forma quantitativo-interpretativa, propondo, a partir das maiores recorrências de opções selecionadas, uma interpretação do contexto relativo aos letramentos acadêmicos em ambas as universidades.

Quadro 2-Questionários aos gestores e coordenadores

\begin{tabular}{|c|c|c|}
\hline GESTORES & COORDENADORES & TIPO \\
\hline $\begin{array}{l}\text { 1. Conhece alguma(s) experiência(s) } \\
\text { didática(s) em prol de letramentos } \\
\text { acadêmicos, em LÍNGUA PORTUGUESA, } \\
\text { destinada(s) aos estudantes dos programas } \\
\text { de pós-graduação em sua universidade } \\
\text { ou instituição (pode incluir iniciativas em } \\
\text { conjunto como outras universidades)? }\end{array}$ & $\begin{array}{l}\text { 1. Conhece alguma(s) experiência(s) didática(s) } \\
\text { em prol de letramentos acadêmicos, em LÍNGUA } \\
\text { PORTUGUESA, destinada(s) aos estudantes dos } \\
\text { programas de pós-graduação coordenado por você } \\
\text { (pode incluir iniciativas em conjunto como outras } \\
\text { universidades)? }\end{array}$ & $\begin{array}{l}\text { Questão de múltipla } \\
\text { escolha (sim ou não) }\end{array}$ \\
\hline $\begin{array}{l}\text { 1.1 Se respondeu SIM na questão anterior } \\
\text { (questão 01), quais são as experiências } \\
\text { relativas aos letramentos acadêmicos, em } \\
\text { LINGUA PORTUGUESA, que ocorrem } \\
\text { em sua universidade (incluindo iniciativas } \\
\text { conjuntas com outras instituições)? Marque } \\
\text { todas as que se aplicam. }\end{array}$ & $\begin{array}{l}\text { 1.1. Se respondeu SIM na questão anterior } \\
\text { (questão 01), quais são as experiências relativas aos } \\
\text { letramentos acadêmicos que ocorrem no curso de } \\
\text { pós-graduação coordenado por você (incluindo } \\
\text { iniciativas conjuntas com outras instituições)? } \\
\text { Marque todas as que se aplicam. }\end{array}$ & $\begin{array}{l}\text { Questão de seleção } \\
\text { de opção(ões) }\end{array}$ \\
\hline $\begin{array}{l}\text { 2. Conhece alguma(s) experiência(s) } \\
\text { didática(s) em prol de letramentos } \\
\text { acadêmicos, em LÍNGUA ESTRANGEIRA, } \\
\text { destinada(s) aos estudantes dos cursos } \\
\text { de pós-graduação de sua universidade ou } \\
\text { instituição (pode incluir iniciativas em } \\
\text { conjunto com outras universidades)? }\end{array}$ & $\begin{array}{l}\text { 2. Conhece alguma(s) experiência(s) didática(s) } \\
\text { em prol de letramentos acadêmicos, em LÍNGUA } \\
\text { ESTRANGEIRA, destinada(s) aos estudantes dos } \\
\text { cursos de pós-graduação coordenado por você } \\
\text { (pode incluir iniciativas em conjunto com outras } \\
\text { universidades)? }\end{array}$ & $\begin{array}{l}\text { Questão de múltipla } \\
\text { escolha (sim ou não) }\end{array}$ \\
\hline $\begin{array}{l}\text { 2.1 Se respondeu SIM na questão anterior } \\
\text { (questão 02), quais são as experiências } \\
\text { relativas aos letramentos acadêmicos que } \\
\text { ocorrem em sua universidade (incluindo } \\
\text { iniciativas conjuntas com outras instituições)? } \\
\text { Marque todas as que se aplicam. }\end{array}$ & $\begin{array}{l}\text { 2.1. Se respondeu SIM na questão anterior } \\
\text { (questão 02), quais são as experiências relativas aos } \\
\text { letramentos acadêmicos que ocorrem no curso de } \\
\text { pós-graduação coordenado por você (incluindo } \\
\text { iniciativas conjuntas com outras instituições)? } \\
\text { Marque todas as que se aplicam. }\end{array}$ & $\begin{array}{l}\text { Questão de seleção } \\
\text { de opção(ões) }\end{array}$ \\
\hline $\begin{array}{l}\text { 2.2 Explicite a(s) língua(s) envolvida na(s) } \\
\text { experiência(s) acima assinaladas. }\end{array}$ & $\begin{array}{l}\text { 2.2. Explicite a(s) língua(s) envolvida na(s) } \\
\text { experiência(s) acima assinaladas. }\end{array}$ & Questão dissertativa \\
\hline-- & $\begin{array}{l}\text { 3. Conhece alguma(s) experiência(s) didática(s) } \\
\text { em prol de letramentos acadêmicos em OUTRO } \\
\text { CURSO DE PÓS-GRADUAÇÃO de sua } \\
\text { universidade ou instituição (independentemente se } \\
\text { em língua portuguesa ou estrangeira)? }\end{array}$ & $\begin{array}{l}\text { Questão de múltipla } \\
\text { escolha (sim ou não) }\end{array}$ \\
\hline-- & $\begin{array}{l}\text { 3.1. Se sua resposta foi SIM na questão anterior } \\
\text { (questão 03), descreva brevemente a(s) experiência(s). } \\
\text { Explicite a(s) língua(s) envolvida na(s) experiência(s) } \\
\text { e em qual(is) instituição(ões) ela(s) ocorre(m) }\end{array}$ & $\begin{array}{l}\text { Questão de seleção } \\
\text { de opção(ões) }\end{array}$ \\
\hline $\begin{array}{l}\text { 4. Conhece alguma(s) experiência(s) } \\
\text { didática(s) em prol de letramentos } \\
\text { acadêmicos em OUTRA universidade ou } \\
\text { instituição (independentemente se em língua } \\
\text { portuguesa ou estrangeira)? }\end{array}$ & $\begin{array}{l}\text { 4. Conhece alguma(s) experiência(s) didática(s) } \\
\text { em prol de letramentos acadêmicos em OUTRA } \\
\text { universidade ou instituição (independentemente se } \\
\text { em língua portuguesa ou estrangeira)? }\end{array}$ & $\begin{array}{l}\text { Questão de múltipla } \\
\text { escolha (sim ou não) }\end{array}$ \\
\hline $\begin{array}{l}\text { 4.1. Se sua resposta foi SIM na questão } \\
\text { anterior (questão 03), descreva brevemente } \\
\text { a(s) experiência(s). Explicite a(s) língua(s) } \\
\text { envolvida na(s) experiência(s) e em qual(is) } \\
\text { instituição(ões) ela(s) ocorre(m) }\end{array}$ & $\begin{array}{l}\text { 4.1. Se sua resposta foi SIM na questão } \\
\text { anterior (questão 04), descreva brevemente a(s) } \\
\text { experiência(s). Explicite a(s) língua(s) envolvida } \\
\text { na(s) experiência(s) e em qual(is) instituição(ões) } \\
\text { ela(s) ocorre(m). }\end{array}$ & $\begin{array}{l}\text { Questão de seleção } \\
\text { de opção(ões) }\end{array}$ \\
\hline
\end{tabular}




\begin{tabular}{|l|l|l|}
\hline $\begin{array}{l}\text { 5. Quais são, em sua opinião, as maiores } \\
\text { necessidades dos estudantes de pós- } \\
\text { graduação no Ensino Superior com } \\
\text { relação ao desenvolvimento de práticas de } \\
\text { letramentos acadêmicos em sua universidade? }\end{array}$ & $\begin{array}{l}\text { 5. Quais são, em sua opinião, as maiores } \\
\text { necessidades dos estudantes de pós-graduação no } \\
\text { Ensino Superior com relação ao desenvolvimento } \\
\text { de práticas de letramentos acadêmicos no curso } \\
\text { coordenado por você? }\end{array}$ & Questão dissertativa \\
\hline $\begin{array}{l}\text { 6. Quais ações, em prol de letramentos } \\
\text { acadêmicos podem contribuir para a } \\
\text { internacionalização de sua instituição? }\end{array}$ & $\begin{array}{l}\text { 6. Quais ações em prol de letramentos acadêmicos } \\
\text { podem contribuir para a internacionalização do } \\
\text { curso coordenado por você? }\end{array}$ & Questão dissertativa \\
\hline $\begin{array}{l}\text { 7. Se desejar, faça outros comentários e } \\
\text { ou sugestões que julgue pertinentes sobre } \\
\text { letramentos acadêmicos. }\end{array}$ & $\begin{array}{l}\text { 7. Se desejar, faça outros comentários que julgue } \\
\text { pertinentes sobre letramentos acadêmicos. }\end{array}$ & Questão dissertativa \\
\hline
\end{tabular}

Fonte: As autoras.

As questões 5, 6 e 7 do questionário foram questões abertas que solicitavam aos respondentes para mencionar, em relação aos letramentos acadêmicos, as necessidades dos alunos, as ações que podem contribuir para a internacionalização da instituição e comentários finais. Para analisar as respostas para essas questões, utilizamos como procedimento analítico a codificação provisória (SALDAÑA, 2009). Essa codificação se caracteriza pela utilização de categorias analíticas pré-determinadas, advindas do estudo da literatura relevante ao tema. No caso deste estudo, examinamos as respostas dos participantes a partir dos modelos de letramentos acadêmicos (LEA; STREET, 1998), a saber: Habilidades de estudo (HE), Socialização acadêmica (SA) e Letramentos acadêmicos (LA). Com isso, objetivamos compreender as concepções mais recorrentes dos respondentes, envolvendo coordenadores e gestores do setor da pósgraduação da instituição, ou seja, aqueles que podem propor políticas com vistas ao desenvolvimento de ações em prol dos Letramentos acadêmicos.

$\mathrm{Na}$ UEL, os questionários foram enviados para os/as coordenadores/as dos cursos de pósgraduação da universidade, diretores/as dos centros de estudos, aos gestores do setor na instituição (Próreitor de Pesquisa e Pós-graduação, Diretor de Pesquisa e Diretora de Pós-graduação). Obtivemos 17 respostas (16 de coordenadores/as de cursos de pós-graduação e 1 diretor de centro). Os respondentes são designados por siglas alfanuméricas, sendo os 16 coordenadores/as de cursos de pós-graduação referidos por R1 a R16 e 1 diretor de centro referido como R17. Na Unespar, os questionários foram enviados para os/as coordenadores/as dos cursos de pós-graduação e gestores (Pró-reitor de Pesquisa e Pós-graduação, Diretora de Pesquisa, Diretora de Pós-graduação). Seis participantes responderam, sendo 4 coordenadores/as de cursos, designados R18 a R21, e dois gestores, referidos como R22 e R23.

No que se concerne à organização metodológica de nossa pesquisa, pautamos nossos estudos na sistematização de procedimentos referentes aos objetivos específicos, à geração de dados e aos critérios de análise, conforme apresentado no Quadro 3.

Quadro 3 - Procedimentos metodológicos

\begin{tabular}{|l|l|l|}
\hline \multicolumn{1}{|c|}{ OBJETIVOS ESPECÍFICOS } & CONJUNTO DE DADOS & PROCEDIMENTOS DE ANÁLISE \\
\hline $\begin{array}{l}\text { 1) mapear as ações de letramentos acadêmicos } \\
\text { em línguas (materna e estrangeiras) em } \\
\text { diferentes cursos de pós-graduação stricto sensu, } \\
\text { mestrado e doutorado, na UEL e na Unespar; }\end{array}$ & $\begin{array}{l}\text { Questionários com gestores e } \\
\text { coordenadores de curso de pós- } \\
\text { graduação da UEL e da Unespar. } \\
\text { Questões de 01 a 04. }\end{array}$ & Quantificação de menções. \\
\hline $\begin{array}{l}\text { 2) identificar as concepções de letramentos } \\
\text { acadêmicos de coordenadores e gestores de pós- } \\
\text { graduação da UEL e Unespar, relacionando-as aos } \\
\text { modelos de letramentos acadêmicos descritos. }\end{array}$ & $\begin{array}{l}\text { Questionários com gestores e } \\
\text { coordenadores de curso de pós- } \\
\text { graduação da UEL e da Unespar. } \\
\text { Questões 05 a 07. }\end{array}$ & $\begin{array}{l}\text { Codificação provisória (SALDAÑA, } \\
\text { 2009), com base nas categorias de } \\
\text { modelos de letramentos acadêmicos } \\
\text { (LEA; STREET, 1998). }\end{array}$ \\
\hline
\end{tabular}

Fonte: As autoras. 
Na próxima seção, discutimos os resultados das análises dos dados obtidos, buscando responder aos objetivos propostos.

\section{Análises e Resultados}

Para responder ao primeiro objetivo, apresentamos uma breve análise quantitativa das respostas dos participantes, apontando as ações mais mencionadas em relação aos letramentos acadêmicos. No que se refere ao segundo objetivo, relacionamos as respostas dissertativas dos participantes aos modelos de letramentos acadêmicos (LEA; STREET, 1998) para identificar as concepções dos respondentes.

No que tange às ações didáticas desenvolvidas na UEL relativas aos letramentos acadêmicos, os respondentes apontaram maior conhecimento de atividades em língua estrangeira (LE) (65\% dos respondentes) do que em língua materna (LM) (12\%), sendo a LE predominante o inglês (79\%). A ação mais mencionada pelos respondentes foi referente a cursos e disciplinas para estudantes da pós-graduação, atividades desenvolvidas pelos próprios cursos ou pela instituição (40\% das ações mencionadas em LM e 36\% das ações mencionadas em LE).

Em relação às ações didáticas desenvolvidas na Unespar, os respondentes também afirmaram conhecer mais ações em LE (84\% das respostas) do que em LM (16\%). De maneira semelhante à UEL, a LE predominante nessas atividades é a língua inglesa ( $84 \%$ das menções). Dentre as ações nomeadas pelos respondentes, a mais recorrente foi cursos e disciplinas para estudantes da pós-graduação, com $50 \%$ das respostas, englobando ações em LM e LE.

Nos gráficos 1 e 2, apresentamos a análise conjunta dos dados obtidos nas duas instituições foco deste estudo. No primeiro gráfico, focamos no conhecimento dos participantes sobre experiências voltadas aos letramentos acadêmicos em sua instituição e ou em outra universidade. No segundo gráfico, expomos os exemplos de ações desenvolvidas nesses contextos.

No Quadro 4, apresentamos a análise das respostas dos participantes às questões concernentes às necessidades e às demandas em relação aos letramentos acadêmicos. A primeira coluna contém o modelo, as segunda e terceira colunas demonstram os excertos dos respondentes, da UEL e Unespar, respectivamente. O mesmo respondente pode aparecer mais de uma vez, pois, resumimos as respostas de três questões. Na sequência, tecemos nossas reflexões em relação a estas análises.

Gráfico 1 - Conhecimento de ações em prol de letramentos acadêmicos na pós-graduação

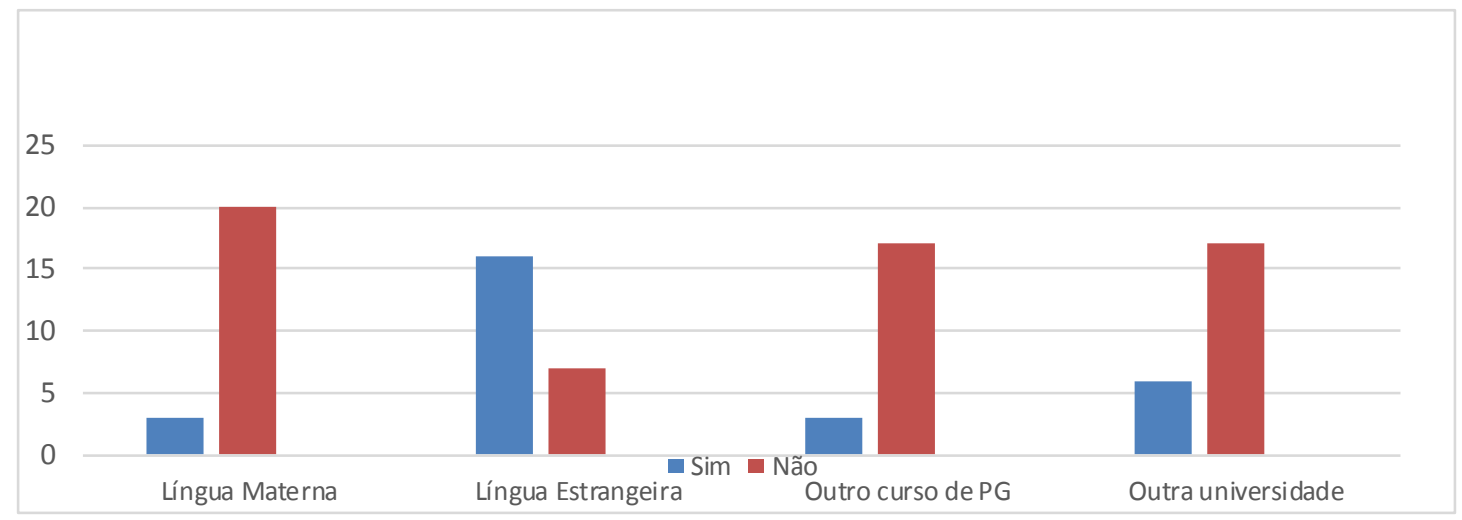

Fonte: As autoras. 
Gráfico 2 - Exemplos de ações em prol de letramentos acadêmicos na pós-graduação

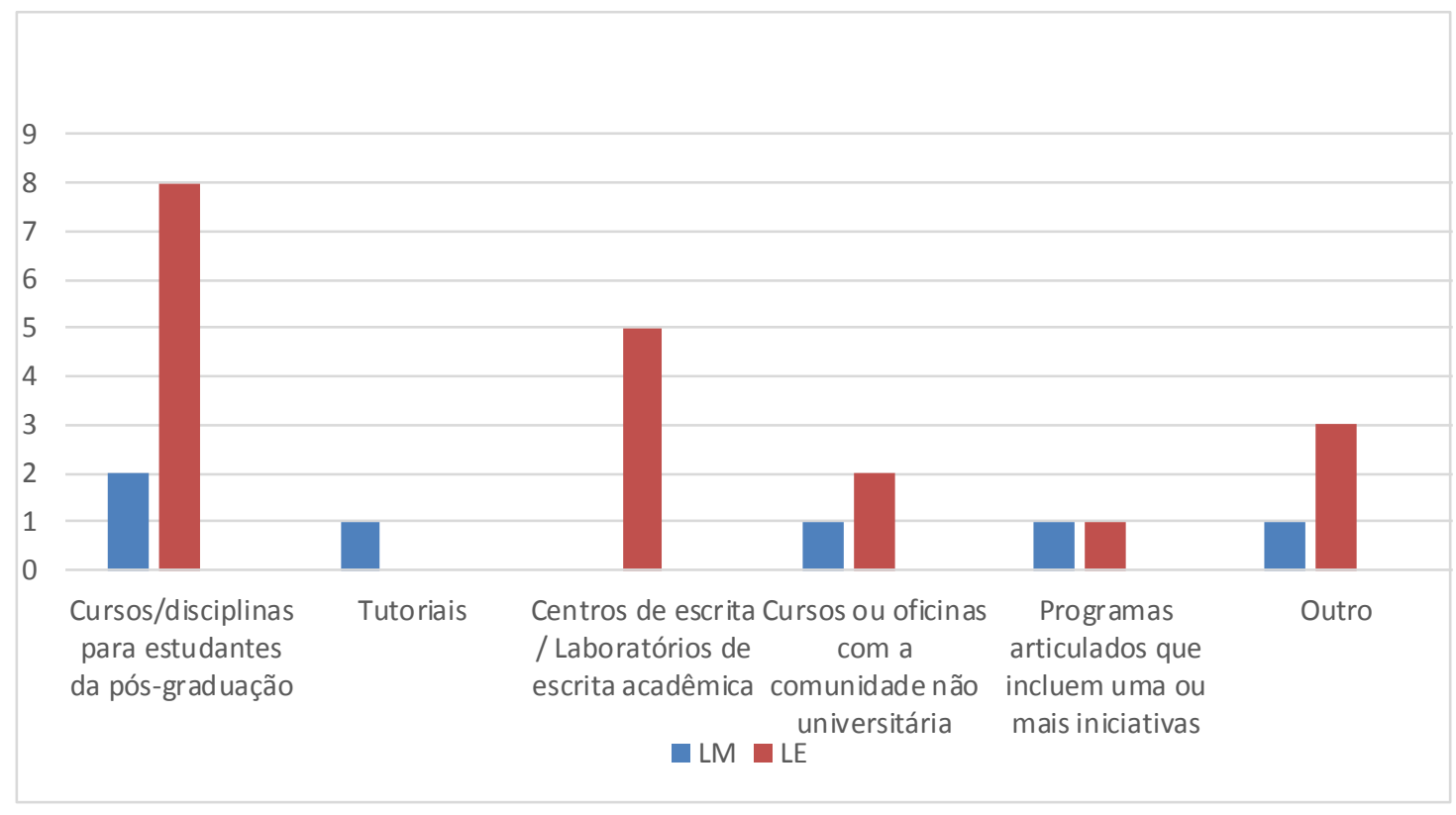

Fonte: As autoras.

Quadro 4 - Concepções dos respondentes em relação aos letramentos acadêmicos

\begin{tabular}{|c|c|c|}
\hline $\begin{array}{c}\text { MODELO DE } \\
\text { LETRAMENTO } \\
\text { ACADEMICO/ } \\
\text { RESPONDENTES }\end{array}$ & UEL & UNESPAR \\
\hline $\begin{array}{l}\text { HABILIDADES DE } \\
\text { ESTUDO (HE) }\end{array}$ & $\begin{array}{l}\text { - leitura e conversação em inglês (R1, R14); oferta } \\
\text { de cursos de línguas para os estudantes (R1); } \\
\text { - conhecimento de língua inglesa (R3); } \\
\text { - escrita em língua inglesa (R4, R8); } \\
\text { - cursos de inglês em geral (R6, R8); } \\
\text { - construção de parágrafos consistentes e } \\
\text { articulados (R8); } \\
\text { - cursos específicos para as demandas do } \\
\text { programa, como a realização de um exame } \\
\text { padronizado de proficiência em inglês, e a } \\
\text { realização do exame TOEFL (para bolsa } \\
\text { sanduíche) (R9); } \\
\text { - língua inglesa ou espanhola, disciplinas, } \\
\text { oficinas nos horários do curso pós (R10); } \\
\text { - escrita formal, apresentação oral, fluência de } \\
\text { leitura e na língua estrangeira (escrita, lida e } \\
\text { falada) (R11); } \\
\text { - interpretação e escrita; fluência em língua } \\
\text { estrangeira (R12); } \\
\text { - leitura e interpretação na língua nativa e } \\
\text { estrangeira (R16); } \\
\text { - linguagem técnica; cursos de línguas } \\
\text { orientais (R17). }\end{array}$ & $\begin{array}{l}\text { - deslocamento de alunos do mestrado para o } \\
\text { exame de proficiência em outras instituições; } \\
\text { falta de professores do campus que possam } \\
\text { ofertar cursos de língua portuguesa, e espanhola } \\
\text { ou inglesa; falta de cursos nas línguas citadas } \\
\text { (R19, R22); cursos voltados para escrita e } \\
\text { oralidade da língua espanhola e inglesa; centro } \\
\text { que possa fornecer exame de proficiência em } \\
\text { língua espanhola e inglesa; cursos de inglês e/ } \\
\text { ou espanhol instrumental; curso de gramática da } \\
\text { língua portuguesa (R19); } \\
\text { - aprender a ler em língua estrangeira; ler e falar } \\
\text { língua estrangeira; identificar alunos(as) que já } \\
\text { fazem uso de língua estrangeira e agrupá-los, a } \\
\text { fim de que eles possam, no mínimo, trabalharem } \\
\text { com seus colegas para lerem textos. (R20); } \\
\text { - disciplinas específicas nos anos iniciais, } \\
\text { disciplinas transversais. (R22); } \\
\text { - ensino de idiomas para docentes e discentes } \\
\text { (R23); }\end{array}$ \\
\hline
\end{tabular}




\begin{tabular}{|c|c|c|}
\hline $\begin{array}{l}\text { SOCIALIZAÇÃO } \\
\text { ACADÊMICA (SA) }\end{array}$ & $\begin{array}{l}\text { - produção de textos acadêmicos, } \\
\text { especificamente, para o nosso Programa, de } \\
\text { textos filosóficos; Produção de artigos, textos, } \\
\text { em língua estrangeira (R2, R6, R15), resumos } \\
\text { e a monografia final do curso (R13); } \\
\text { - suporte/cursos para a escrita de textos } \\
\text { acadêmicos e de conteúdos para aulas em } \\
\text { língua inglesa (R4), R6) específicas para o } \\
\text { próprio curso (R5); } \\
\text { - preenchimento do currículo Lattes, da } \\
\text { Plataforma Brasil, etc.; cursos de curta } \\
\text { duração com temáticas específicas para as } \\
\text { dificuldades apresentadas (R7); } \\
\text { - disciplinas integradas e focadas nas } \\
\text { especificidades da área (R11); } \\
\text { - disciplina de inglês técnico como optativa } \\
\text { em parte da CH do curso (R12); } \\
\text { - programas de orientação e capacitação } \\
\text { (R15). }\end{array}$ & $\begin{array}{l}\text { - iniciativas importantes; colaboração efetiva } \\
\text { para uma nova ideia de universidade e de pós- } \\
\text { graduação (R18); } \\
\text { - escrita científica (dificuldade de muitos } \\
\text { estudantes com a redação de artigos científicos e } \\
\text { da própria elaboração da dissertação; planejado } \\
\text { de forma organizada e aplicados a todos } \\
\text { os discentes independente das dificuldades } \\
\text { encontradas (R21); } \\
\text { - atividades que tenham como foco a } \\
\text { aprendizagem de letramento; necessidade do } \\
\text { letramento acadêmico em todos os cursos de } \\
\text { graduação e pós-graduação (R22); } \\
\text { - redação científica em português e em inglês } \\
\text { (R23). }\end{array}$ \\
\hline $\begin{array}{l}\text { LETRAMENTO } \\
\text { ACADÊMICO (LA) }\end{array}$ & $\begin{array}{l}\text { - colaborações científicas diretas com } \\
\text { instituições de outros países (R9); } \\
\text { - eventos que exijam apresentações em língua } \\
\text { estrangeira (R12); } \\
\text { - participação dos estudantes em eventos } \\
\text { internacionais (R13). }\end{array}$ & $\begin{array}{l}\text { - ações que possibilitem efetivar a } \\
\text { internacionalização (R18); } \\
\text { - parcerias com outros programas de pós- } \\
\text { graduação estrangeiros e o intercâmbio entre } \\
\text { discentes e docentes (R21). }\end{array}$ \\
\hline
\end{tabular}

Fonte: As autoras.

Conforme demonstramos no Quadro 4, os participantes compreendem letramentos acadêmicos, principalmente, de acordo com os modelos de Habilidade de estudo e Socialização acadêmica. Dos 23 respondentes, 16 referem-se ao primeiro modelo e 14 ao segundo. Somente cinco respostas continham trechos relacionados ao modelo de Letramentos acadêmicos.

As respostas que representam o modelo de Habilidade de estudo são aquelas que demonstram o entendimento de que, para que o/a estudante consiga participar das práticas sociais acadêmicas, ele/a precisa aprender a língua (em termos de gramática, habilidades de leitura e escrita, entre outros aspectos). Nesse modelo, não se leva em consideração as especificidades das ações linguageiras praticadas na academia ou os gêneros produzidos nessa esfera de atuação (como Artigo, Resumo ou outros gêneros de texto). Parece haver o entendimento de que basta saber o código da língua e suas habilidades, em geral, para se conseguir compreender e produzir gêneros acadêmicos e, portanto, participar das práticas sociais acadêmicas.

Os trechos relacionados ao modelo de Socialização acadêmica referem-se à língua em suas especificidades acadêmicas, uma vez que mencionam gêneros da esfera acadêmica (Artigo, Resumo, Monografia, dentre outros), assim como apontam a necessidade de desenvolvimento de atividades específicas para seu curso, programa e área. Desse modo, os respondentes reconhecem que cada área de conhecimento tem especificidades, construindo conhecimento de maneiras diferentes, muito embora, a nosso ver, a ciência seja vista, neste momento, como algo homogêneo. Ou seja, produzir um Resumo, por exemplo, pode ser considerado algo igual a todos os campos do conhecimento. Portanto, parece haver uma compreensão de que não basta o/a estudante aprender a língua em termos gerais, mas de que precisa também ser inserido nas práticas sociais no que se refere à leitura e à escrita na esfera acadêmica, mesmo que de modo acrítico. 
Em relação ao modelo de Letramentos acadêmicos, identificamos as respostas que demonstram consideração ao uso da língua em situações reais no contexto acadêmico, como participação em eventos científicos e colaboração de pesquisa com instituições internacionais. Esse modelo engloba os dois primeiros, além de atentar para questões referentes a "relações de poder, autoridade, construção de sentido e identidade que estão implícitas no uso das práticas de letramentos dentro de configurações institucionais específicas" (LEA; STREET, 1998, p. 370), conforme mencionamos na discussão teórica norteadora deste trabalho. Nesse sentido, entendemos que o/a acadêmico/a pode experienciar e compreender essas questões a partir da vivência real de práticas de letramentos acadêmicos, já que é nas práticas em contextos reais que esses elementos podem ser mais bem evidenciados.

Com base nestas análises, concluímos que as concepções dos/as coordenadores/as de cursos e gestores/as do setor de pós-graduação da UEL e da Unespar, em relação aos letramentos acadêmicos, referem-se principalmente ao entendimento de língua em seu nível superficial. Em outras palavras, para compreender e produzir gêneros específicos da esfera acadêmica, o foco das ações deve estar em ensinar línguas em seu aspecto geral, com foco em aspectos formais e habilidades (modelo de Habilidades de ensino). Muitos respondentes também compartilham a concepção de que há especificidades para as práticas de letramento acadêmico e que, portanto, é necessário ensinar os/as estudantes a compreender e produzir gêneros textuais da esfera acadêmica, incluindo as particularidades de cada área do conhecimento (modelo de Socialização acadêmica). Por fim, poucos respondentes referem-se às práticas linguageiras em suas situações reais de uso, concepção esta que possibilita a vivência e a compreensão de questões de poder, autoridade, identidade, em seus contextos reais (modelo de Letramentos acadêmicos).

Enfim, os resultados das análises nos apontam algumas limitações no campo da construção de conhecimentos no que tange aos Letramentos acadêmicos, indicando-nos um caminho ainda a ser trilhado nessa perspectiva. Daí a importância deste trabalho e de muitos outros que poderão contribuir para o ensino de línguas e as práticas formativas na pós-graduação com vistas ao desenvolvimento acadêmico e científico.

\section{Considerações Finais}

As análises nos permitiram identificar algumas lacunas no contexto de pós-graduação no que diz respeito à concepção de letramentos acadêmicos, porém, ao mesmo tempo, tal constatação serve de contribuição e de motivação para repensarmos e ressignificarmos algumas práticas formativas no sentido de propiciar possíveis encaminhamentos aos contextos investigados.

No que concerne aos nossos objetivos específicos, referentes à identificação das concepções de letramentos acadêmicos de coordenadores e gestores de pós-graduação da UEL e Unespar, bem como à identificação de modelos, no contexto universitário, para a formação e o desenvolvimento social e profissional do estudante de pós-graduação, constatamos alguns aspectos. O modelo de maior recorrência em respostas de coordenadores e gestores é aquele relativo às Habilidades específicas, a partir de uma compreensão homogênea de escrita e destituída de sua função social, talvez em função da falta de oportunidades no próprio contexto que pudessem conduzir a uma ampliação desses conhecimentos. Assim, as análises nos permitiram reconhecer que há muito a ser feito para avançarmos nas práticas formativas em contextos de pós-graduação junto à proposta de ensino de línguas com o intuito de ampliar as ações para chegarmos a propostas que atendam à perspectiva dos Letramentos acadêmicos.

Nesse sentido, esperamos que nossa proposta de discussão possa contribuir para a ressignificação das práticas formativas em contextos de pós-graduação, razão pela qual, em uma próxima etapa da pesquisa, serão implementadas ações em prol de Letramentos acadêmicos constantes do Laboratório Integrado de Letramentos Acadêmico-científicos (LILA), decorrentes da fase de mapeamento. 


\section{REFERÊNCIAS}

BARTON, D. Literacy: an Introduction to the Ecology of Written Language. Londres: Blackwell, 1994.

BEZERRA, B. Letramentos acadêmicos e construção da identidade: a produção do artigo científico por alunos de graduação. Linguagem em (Dis)curso - LemD, v. 15, n. 1, p. 61-76, jan./abr. 2015.

CRISTOVÃO, V. L. L.; VIGNOLI, J. S. Ações de Didatização de Gêneros em prol de Letramentos Acadêmicos: práticas e demandas. Horiz̧ontes, v. 38, n. 1, p. 1-18, 2020.

FIAD, R. S. A escrita na universidade. Revista da ABRALIN, n. Especial, $2^{a}$ parte, p. 357-369. 2011. Disponível em: http://www.abralin.org/revista/RVE2/14v.pdf. Acesso em: 05 jan. 2019.

GEE, J. P. Social linguistics and literacies: ideology in discourses. 2. ed. London; Philadelphia: The Farmer Press, 1996.

IVANIC, R. Discourses of writing and learning to write. Language and Education, v. 18, n. 3, p. 220-245, 2004.

JONES, C.; TURNER, J.; STREET, B. (org.). Students writing in the university: cultural and epistemological issues. Amsterdam. John Benjamins, 1999.

LEA, M. R.; STREET, B. V. Student writing in higher education: an academic literacies approach. Studies in Higher Education, v. 23, n. 2, p. 157-172, June 1998.

LEA, M. R.; STREET, B. V. Writing as academic literacies: understanding textual practices in higher education. In: CANDLIN, C.N.; HYLAND, K. (eds). Writing: texts, processes and practices. London: Longman; 1999. p. 62-81.

LEA, M. R.; STREET, B. V. The «Academic Literacies» Model: Theory and Applications. Theory Into Practice, v. 45, n. 4, p. 368-377, 2006.

LEA, M. R.; STREET, B. V. O modelo de «letramentos acadêmicos»: teoria e aplicações. Filologia e Linguística Portuguesa, v. 16, n. 2, p. 477-493, jul./dez. 2014.

LILLIS, T.; SCOTT, M. Defining academic literacies research: issues of epistemology, ideology and strategy. Journal of Applied Linguistics, v. 4, n. 1, p. 5-32, 2007. Disponível em: https://bit.ly/2JJuzJo. Acesso em: 2 nov. 2016.

PAIVA, V. L. M. de O. Manual de pesquisa em estudos linguísticos. São Paulo: Parábola Editorial, 2019.

SALDAÑA, J. The coding manual for qualitative researchers. London; Thousand Oaks, CA: Sage Publications, 2009.

STREET, B. V. Literacy in theory and practice. London: Cambridge University Press, 1984.

STREET, B. V. Cross-Cultural Approaches to Literacy. Cambridge: Cambridge University Press, 1994. 
STREET, B. V. Social Literacies: Critical Approaches to Literacy Development, Ethnography and Education. London: Longman, 1995.

STREET, B. V. Dimensões escondidas na escrita de artigos acadêmicos. Perspectiva, Florianópolis, v. 28, n. 2, p. 541-457, 2010. 